\title{
PENGANGKATAN SEKRETARIS DESA MENJADI PNS DALAM MENDUKUNG PENYELENGGARAAN PEMERINTAHAN DESA DI KABUPATEN CIREBON
}

\author{
Nina Karlina \\ Departemen Administrasi Publik FISIP Unpad \\ E-mail : karlina_nina@yahoo.com
}

\begin{abstract}
Abstrak : Pemerintahan Desa sebagai lembaga perpanjangan pemerintah pusat memiliki peran yang strategis yang memerlukan peraturan yang berkaitan dengan pemerintahan desa yang mengatur tentang pemerintahan desa, sehingga roda pemerintahan berjalan dengan optimal. Untuk mewujudkan sistem pelayanan yang nyata maka perubahan sistem pemerintah desa mutlak diperlukan. Salah satu kebijakan Pemerintah Pusat adalah yang tertuang dalam Pasal 202 ayat (3) Undang-Undang Nomor 32 tahun 2004, yang menjelaskan paling mendasar dalam perubahan sistem Pemerintahan Desa adalah adanya pengangkatan Sekretaris Desa dari Pegawai Negeri Sipil. Pengangkatan sekretaris desa menjadi PNS di lingkungan Kabupaten Cirebon memberikan dampak bagi penyelenggaraan pemerintahan desa. Mereka diharapkan dapat memberikan pelayanan kepada masyarakat yang lebih baik sesuai dengan tugas pokok dan fungsinya. Dengan memahami bahwa masyarakat adalah pelanggan utama yang harus dilayani, maka sekdes diharapkan dapat mengetahui dan memahami apa yang dibutuhkan dan diinginkan masyarakat, sehingga dapat memuaskan masyarakat dengan pelayanan prima. Namun dalam pengangkatan sekdes menjadi PNS masih terdapat permasalahan yang bermunculan yaitu kecemburuan sosial di dalam kantor desa akibat tuntutan perangkat desa selain sekretaris desa untuk diangkat menjadi PNS. Hal inilah yang memberikan iklim tidak baik di dalam kantor desa.
\end{abstract}

Kata Kunci: Sekretaris Desa, Pemerintahan Desa

\section{APPOINTMENT VILLAGE GOVERNMENT SECRETARY BECAME CIVIL SERVICE (PNS) IN SUPPORTING OF VILLAGE GOVERNMENT IN THE CIREBON DISTRICT}

\begin{abstract}
The village government as an extension of the central government has a strategic role that requires government regulation relating to village governing village governance, so that the wheels of government running optimally. To realize the effective service, central government set out in Article 202 paragraph (3) of Law No. 32 of 2004, which describes the most fundamental change in the system is the removal of the Village Government Secretary of the Civil Service. Appointment of secretary of the village became a civil servant in Cirebon environment impacting village government. They are expected to provide the public a better fit with the duties and functions. With the understanding that the community is a major customer to be served, then the Village Government expected to know and understand what is needed and wanted by the public, so as to satisfy the public with excellent service. But the changes of secretary of the village became a civil servant still has problems. They are social jealousy in the office of the village from other villages device, they claims has the equal rights became Civil Service (PNS). This is what gives the bad situation in the village office
\end{abstract}

Keywords: Village Government Secretary, Village Government

\section{PENDAHULUAN}

Pemerintahan Desa merupakan lembaga per-panjangan pemerintah pusat memiliki peran yang strategis dalam pengaturan masyarakat desa/kelurahan dan keberhasilan pembangunan nasional. Karena perannya yang besar, maka perlu adanya Peraturan-peraturan atau Undang-Undang yang berkaitan dengan pemerintahan desa yang mengatur tentang pemerintahan desa, sehingga roda pemerintahan berjalan dengan optimal.

Salah satu agenda penting penataan yang lebih menyeluruh adalah penataan di level desa. Rakyat yang hendak dilayani tidak lain adalah masyarakat yang berada di pedesaan. Peningkatan kualitas SDM agar dapat melakukan peningkatan kualitas publik merupakan kebutuhan yang mendesak. Pengembangan SDM dituntut untuk menghasilkan aparat-aparat birokrasi yang memiliki kemampuan yang memadai dalam perumusan dan pelaksanaan kebijakan pemerintah, termasuk dalam hal memberikan pelayanan terhadap masyarakat. Untuk mewujudkan sistem pelayanan yang nyata maka perubahan sistem pemerintah desa mutlak diperlukan.
Salah satu kebijakan Pemerintah Pusat adalah yang tertuang dalam Pasal 202 ayat (3) UndangUndang Nomor 32 tahun 2004, "Sekretaris Desa sebagaimana dimaksud pada ayat (2) diisi dari Pegawai Negeri Sipil yang memenuhi persyaratan" serta dalam penjelasannya menyatakan "Sekretaris Desa yang selama ini yang bukan Pegawai Negeri Sipil secara bertahap diangkat menjadi Pegawai Negeri Sipil sesuai dengan perundang-undangan.“ dalam pasal ini menjelaskan bahwa yang paling mendasar dalam perubahan sistem Pemerintahan Desa adalah adanya pengangkatan Sekretaris Desa dari Pegawai Negeri Sipil.

Pemerintahan Kabupaten Cirebon merupakan kabupaten yang berbatasan langsung dengan provinsi Jawa Tengah dan memiliki karakteristik daerah yang khas, sebab berada di wilayah pantai utara Jawa Barat hingga memiliki potensi wilayah yang besar baik dari perairan lautnya maupun dari perindustrian dan bidang jasa maupun parawisata, menyebabkan daerah ini termasuk kabupaten yang termaju di Provinsi Jawa Barat. 
Melihat kondsi tersebut, seharusnya pemeirntahan desa di Kabupaten Cirebon dapat memberikan pelayanan terbaik bagi masyarakatnya, terutama dengan dikeluarkannya Peraturan Pemerintah mengenai pengangkatan Sekretaris Desa menjadi PNS, seharusnya dapat meningkatkan kualitas pelayanan Desa bagi masyarakatnya.

Berdasarkan uraian tersebut melalui penelitian ini penulis berupaya untuk untuk mengetahui Dampak pengangkatan Sekretaris Desa Menjadi Pegawai Negeri Sipil dalam efektiftas penyelenggaraan pemerintahan desa di Kabupaten Cirebon.

Tujuan penelitian ini adalah teridentifikasi dampak pengangkatan sekretaris desa menjadi PNS dan bagaimana efektifitasnya dalam pemerintahan desa.

Dalam penelitian ini akan melihat melihat karakteristik desa dengan mengungkapkan definisi desa. Kemudian mengenai pelayanan publik.

Pengertian desa dapat juga dilihat dari pergaulan hidup, seperti yang dikemukakan oleh Bouman (dalam Beratha, 1982:26) yang mendefenisikan desa: "Sebagai salah satu bentuk kuno dari kehidupan bersama sebanyak beberapa ribu oang, hampir semuanya saling mengenal; kebanyakan yang termasuk di dalamnya hidup dari pertanian, perikanan dan sebagainya, usaha yang dapat dipengaruhi oleh hukum dan kehendak alam. Dan dalam tempat tinggal itu terdapat banyak ikatan-ikatan keluarga yang rapat, ketaatan pada tradisi dan kaidah-kaidah sosial".

Lebih lanjut Sutardjo Kartohadikusumo (1953:2) menyatakan bahwa : "Desa merupakan suatu kesatuan masyarakat hukum dimana bertempat tinggal suatu masyarakat yang berkuasa mengadakan pemerintahan sendiri".

Selain itu ada beberapa hal yang perlu diperhatikan yaitu tentang unsur-unsur desa. Menurut Bintarto (1983:13) unsur-unsur yang harus ada dalam suatu desa adalah; a. Daerah, dalam arti tanah-tanah yang produktif dan yang tidak produktif beserta penggunaannya, termasuk juga unsur lokasi, luas dan batas yang merupakan lingkungan geografis setempat. b. Penduduk, adalah hal yang meliputi jumlah, pertambahan, kepadatan, persebaran dan mata pencaharian penduduk desa setempat; c. Tata Kehidupan, dalam hal ini pola tata pergaulan dan ikatan-ikatan pergaulan warga desa. Jadi menyangkut seluk beluk kehidupan masyarakat desa (rural society).

Secara sosiologis, masyarakat Desa memiliki karakteristik tertentu yang membedakannya dengan kelompok masyarakat lainnya. Boeke (1971: 9) misalnya memberikan gambaran bahwa yang dimaksud dengan Desa adalah: persekutuan hukum pribumi yang terkecil dengan: a. Kekuasaan sendiri; b. Daerah sendiri; c. Kekayaan/pendapatan sendiri.

Dapat dikatakan bahwa yang termuat dalam undang-undang secara jelas menempatkan desa sebagai suatu organisasi pemerintahan atau organisasi kekuasaan, yang secara politis memiliki wewenang tertentu untuk mengatur warga atau anggota komunitasnya. Baik sebagai akibat posisi politisnya yang merupakan bagian dari negara atau hak asal usul dan adat istiadat yang dimilikinya. Namun demikian dalam pengertian ini masih belum tergambarkan secara jelas mengenai kualitas otoritas yang dimiliki desa, terutama berkaitan dengan kekuatan politik di atasnya, yakni negara.

Munculnya otoritas politik di dalam suatu komunitas yang disebut dengan desa secara internal mudah dipahami, dengan melihat sejarah perkembangannya. Secara faktual jumlah penduduk bertambah dan masalah-masalah berkait dengan kepentingan masyarakat bertambah. Kenyataan tersebut sudah barang tentu mendorong munculnya suatu otoritas yang diharapkan dapat mengatasi berbagai persoalan yang merealisasi aspirasi yang berkembang. Dari situ lahir kesatuan masyarakat hukum yang mandiri dan pemimpin mereka biasanya adalah yang tertua atau memiliki kemampuan paling tinggi diantara mereka (Maschab, 1992).

\section{METODE}

Penelitian ini lebih bersifat deskriptif yaitu suatu jenis penelitian yang mengungkapkan mengenai suatu masalah apa adanya, sesuai dengan kenyataan yang ada di lapangan. Penggunaan metode kualitatif dilaksanakan sesuai dengan karakteristik yang ada yaitu secara langsung terlibat di lokasi penelitian melalui pengamatan peran serta (participant observation).

Informan dalam penelitian ini adalah:

1. Sekretaris Desa di Kabupaten Cirebon dengan menggunakan Purposif yaitu mengambil pada desa tertentu sesuai dengan kebutuhan oenelitian.

2. Aparat pemerintahan desa terpilih dan masyarakat penerima pelayanan pada desa

\section{HASL DAN PEMBAHASAN}

Cirebon merupakan salah satu kabupaten terpadat di Jawa Barat. Penduduk Kabupaten Cirebon terus bertambah, meski demikian dari sensus ke sensus, tren rata-rata laju pertumbuhan penduduk dari sensus ke sensus semakin melambat. Pada Tahun 1980 jumlah penduduk Kabupaten Cirebon baru berjumlah 1.331.690 jiwa dan pada tahun 1990 tercatat 1.648.021 jiwa. Sepuluh tahun kemudian pada tahun 2000 penduduk Kabupaten Cirebon menjadi 1.931.068 jiwa. Hasil sementara dari pengolahan data SP2010-L1. P212, SP2010-C2, dan SP2010-L2 (kondisi 15 Juli 2010) sebesar 2.065.142 jiwa dengan komposisi 1.057.501 jiwa penduduk laki-laki dan 1.007.641 jiwa penduduk perempuan.

Menurut angka sementara hasil Sensus Penduduk Indonesia 2010, Kecamatan Sumber merupakan wilayah dengan jumlah penduduknya paling banyak yaitu sebesar 80.914 jiwa dan berikutnya adalah Kecamatan Gunungjati yaitu sebanyak 77.712 jiwa. Sedangkan wilayah dengan jumlah penduduk paling sedikit di Kabupaten Cirebon adalah Kecamatan Pasaleman yaitu sebanyak 24.912 jiwa dan Kecamatan Karangwareng sebanyak 26.554 jiwa.

Kabupaten Cirebon terdiri atas 40 kecamatan, yang dibagi lagi atas 412 desa dan 12 kelurahan. Pusat pemerintahan Kabupaten Cirebon di Kecamatan 
Sumber, yang berada di sebelah selatan Kota Cirebon. Tiga kecamatan yang baru terbentuk pada tahun 2007 adalah Kecamatan Jamblang (Pemekaran Kecamatan Klangenan sebelah timur), Kecamatan Suranenggala (Pemekaran Kecamatan Kapetakan sebelah selatan), dan Kecamatan Greged (Pemekaran Kecamatan Beber sebelah timur).

Dengan memiliki kecamatan yang yang cukup banyak serta jumlah desa hingga 412 desa, maka terdapat 412 sekretaris desa yang harus menjadi PNS. Maka dengan jumlah 412 tersebut harus memberikan pelayanan yang terbaik bagi masyarakat.

Dalam melihat efektifitas dalam penyelenggaraan pemerintahan desa dengan diangkatnya Sekretaris Desa menjadi PNS sebenarnya dapat dilihat dari bagaimana desa menyikapi dengan diangkatnya sekretaris desa menjadi PNS serta dampak bagi pelayanan desa kepada masyarakat terutama dalam pembangunan desa itu sendiri.

Dengan adanya otonomi desa menyebabkan desa menjadi ujung tombak dalam pelayanan pemerintahan. Terutama dalam pembangunan desa dalam pengelolaan pemerintahan menjadi sangat penting dan harus ada peran-peran yang terlibat di dalamnya, yaitu aparat desa itu sendiri, partisipasi masayrakat dan peran swasta. Maka dari itu jika melihat sekretaris desa menjadi PNS untuk dampaknya terhadap pengelolaan pemeirntahan desa hanya memberikan dampak internal di kantor desa itu sendiri. Sedangkan untuk pengelolaan desa dalam pembangunan desa ada peran lainnya yang memberikan dampak cukup besar.

Dalam kasus di Cirebon sudah terdapat upaya untuk meningkatkan kompetensi yang dimilik oleh sekretaris desa dengan mmeberikan pelatihan-pelatihan. Pelatihan yang dilakukan melalui Diklat Peningkatan Kompetensi Sekdes yang diselenggarakan oleh Badan Kepegawaian Pendidikan dan Pelatihan Daerah Kabupaten Cirebon, selama 14 (empat belas) hari. Diklat tersebut merupakan diklat gelombang terakhir yang dilaksanakan pada tanggal 23 November hingga 7 Desember 2011. Diklat gelombang pertama telah dilaksanakan pada tahun 2010.

Sekdes yang mengikuti diklat tahun ini berjumlah 104 orang. Mereka diharapkan dapat memberikan pelayanan kepada masyarakat yang lebih baik sesuai dengan tugas pokok dan fungsinya. Dengan memahami bahwa masyarakat adalah pelanggan utama yang harus dilayani, maka sekdes diharapkan dapat mengetahui dan memahami apa yang dibutuhkan dan diinginkan masyarakat, sehingga dapat memuaskan masyarakat dengan pelayanan prima

Mengingat sekdes merupakan ujung tombak pemerintah daerah, maka BKPPD berkewajiban untuk memperkaya keilmuan, pengetahuan dan wawasan sekdes guna pemenuhan kebutuhan penciptaan aparatur pemerintahan yang handal dan professional. Hal ini dipertegas dengan Surat Edaran Menteri Dalam Negeri Nomor 890/1615/SJ tanggal 12 Mei 2009 tentang Pendidikan dan Pelatihan Peningkatan Kompetensi Sekdes.
Upaya-upaya yang telah dilakukan oleh pemerintahan Cirebon dalam mengoptimalkan peran dan fungsi pemerintah Desa dengan memberikan upaya peningkatan kompetensi bagi jajaran personel perangkat desa agar memadai dalam pengelolaan pemerintahan desa, mulai dari segi pendidikan, pengetahuan dan kemampuan, penguasaan terhadap bidang tugasnya masing-masing.

Di Kabupaten Cirebon secara bertahap telah dilakukan pembenahan dan penertiban perangkat desa terutama dari segi administrasi yang penyangkut pembaharuan terhadap surat-surat keputusan tentang pengetahuan perangkat desa berikut pengadaan personil.

Dengan demikian, diangkatnya sekretaris desa menjadi PNS memeberikan dampak cukup baik bagi penyelenggaraan pemerintahan desa. Walaupun demikian masih terdapat permasalahan yang muncul karena timbul kecemburuan dalam perangkat desa. Hal inilah yang menyebabkan banyak perangkat desa yang menuntut diangkat pula menjadi PNS dengan menuntut diadakannya revisi terbatas terhadap UU No. 32/2004. Untuk pasal 202 ayat 3, diusulkan agar Sekdes dan perangkat desa lainnya diangkat menjadi PNS, dari sebelumnya berbunyi Sekdes dan perangkat desa diisi dari PNS yang memenuhi persyaratan.

Hal inilah yang menyebabkan terganggunya jalannya pemerintahan desa, sebab kondisi internal di kantor desa yang kurang kondusif dalam memberikan pelayanan pemerintahan desa. Namun hal inilah yang menuntut peran dari pimpinan desa yaitu kepala desa agar dapat memberikan pengaruh dalam situasi kebersamaan dalam kantor desa.

\section{SIMPULAN}

pengangkatan sekdes menjadi PNS di lingkungan Kabupaten Cirebon memberikan dampak bagi penyelenggarahan pemerintahan desa. Mereka diharapkan dapat memberikan pelayanan kepada masyarakat yang lebih baik sesuai dengan tugas pokok dan fungsinya. Dengan memahami bahwa masyarakat adalah pelanggan utama yang harus dilayani, maka sekdes diharapkan dapat mengetahui dan memahami apa yang dibutuhkan dan diinginkan masyarakat, sehingga dapat memuaskan masyarakat dengan pelayanan prima

Namun dalam pengangkatan Sekdes menjadi PNS masih terdapat permasalahan yang bermunculan yaitu kecemburuan sosial di dalam kantor desa akibat tuntutan perangkat desa selain sekretaris desa untuk di angakat menjadi PNS. Hal inilah yang memberikan iklim tidak baik di dalam kantor desa.

Berdasarkan hasil penelitian tersebut, maka saran untuk kondisi yang terjadi adalah:

1. Bagi pemerintahan pusat harus melihat dampak dari suatu kebijakan. Dengan demikian dalam kebijakan selanjutnya harus dapat memberikan iklim baik dalam pemerintaaahan desa. Kebijakan ini juga dapat difasilitasi oleh kebijakan dalam lingkungan tingkat II seperti Kabupaten Cirebon 
2. Pelatihan-pelatihan dalam peningkatan kompetensi sekretaris desa harus dilakukan secara bertahap dan kontinuitas, sebab sekretaris desa yang menjadi PNS tidak merata baik secara usia, pendidikan dan pengalamannya dalam pemerintahan desa.

3. Membangun iklim baik dalam kantor desa dengan mengoptimal peran sekretaris desa dan juga kepala desa sebagai pimpinan di pemerintahan desa.

\section{DAFTAR PUSTAKA}

Alderfer, Harold F. 1964. Local Government in Developing Countries, New York : Mc Graw-Hill Book Company.

Bertha, I Nyoman. 1991. Pembangunan Desa Berwawasan Lingkungan. Jakarta: Bumi Aksara

Cook, Sarah dan Steve Macaulay. 1996. Perfect Empowerment. Elex Media Computindo. Jakarta.

Kuncoro, Mudrajat (1997) “Otonomi Daerah dalam Transisi", pada Seminar Nasional Manajemen Keuangan Daerah dalam Era Global, 12 April, Yogyakarta.
Osborne, David and Ted Gaebler (1993) Reinventing Government: How the Entrepreneurial Spirit Is Transforming the Public Sector. Penguins Books, New York.

Republik Indonesia, Undang-Undang No. 32 tahun 2004 tentang Pemerintahan Daerah.

,Undang-Undang No. 33 tahun 2004 tentang Perimbangan Keuangan Antara Pemerintah Pusat dan Daerah.

Smith, Brian C. 1985. Decentralization : The Territirial Demension of the State. London : Allen \& Unwin.

Ter-Minassian, Teresa. 1997. “ Decentralizing government" Finance \& Development, 34, 3 ( September 1997 ), 36-39.

The Liang Gie. 1968. Pertumbuhan Pemerintahan darah di Negara Republik Indonesia : Suatu analisa tentang masalah-masalah Desentralisasi dan cara-cara Penyelesaiannya. Jakarta: Gunung Agung. 